White, G. F., R. W. Kates, and I. Burton, 2001. "Knowing Better and Losing Even More: the Use of Knowledge in Hazards Management," Environmental Hazards, Vol. 3, pp. 81-92.

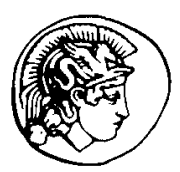

PERGAMON

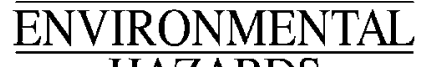
HAZARDS

www.elsevicr.com/locate/hazards

\title{
Knowing better and losing even more: the use of knowledge in hazards management
}

\author{
Gilbert F. White $^{\mathrm{a}, *}$, Robert W. Kates ${ }^{\mathrm{b}}$, Ian Burton ${ }^{\mathrm{c}}$ \\ ${ }^{a}$ Institute of Behavioral Science, University of Colorado, Boulder, CO 80309-0482, USA \\ b33 Popple Point, Trenton, ME 04605, USA \\ ${ }^{\mathrm{c}}$ Meteorological Service of Canada, 4905, Dufferin Street, Downsview, Ont., Canada M3 H 5T4
}

\begin{abstract}
Although loss of life from natural hazards has been declining, the property losses from those causes have been increasing. At the same time the volume of research on natural hazards and the books reviewing findings on the subject have also increased. Several major changes have occurred in the topics addressed. Emphasis has shifted from hazards to disasters. There has been increasing attention to vulnerability. Views of causation have changed. Four possible explanations are examined for the situation in which more is lost while more is known: (1) knowledge continues to be flawed by areas of ignorance; (2) knowledge is available but not used effectively; (3) knowledge is used effectively but takes a long time to have effect; and (4) knowledge is used effectively in some respects but is overwhelmed by increases in vulnerability and in population, wealth, and poverty. C) 2002 Elsevier Science Ltd. All rights reserved.
\end{abstract}

\section{Introduction}

Both estimated losses from natural hazards and understandings about them have increased during the past decade. Several published estimates of average annual economic losses including insured losses, have appeared, invariably showing dramatic increases, although the soundness and comparability of the data are questionable (Munich Re-Insurance, 2001; International Red Cross, 2001). At the same time there are new books about natural hazards, and an immense enlargement of the literature on research findings appearing in scientific journals. How do those books and the research and understanding they summarize relate to the evidently growing toll of losses? Is human knowledge and understanding of the causes of the losses inadequate despite the research effort, or is it that existing knowledge is not applied, or not used in an effective fashion? Could there be other explanations that lie outside our scholastic assumption that knowledge has a key role to play?

\footnotetext{
*Corresponding author. Tel.: +1-303-492-6311; fax: + 1-303-4922151.

E-mail address: gilbert.white@colorado.edu (G.F. White).
}

Many of the single- or multi-authored volumes in English on natural hazards that have appeared in the last decade were designed as texts and might be expected to influence the approaches taken by a new generation of investigators and practitioners. We have based this review upon 12 of those selected as relatively comprehensive in their converge of natural hazards and reflecting the current state of knowledge (Table 1). Two (Lindell and Perry, 1992; Quarantelli, 1998) deal chiefly with theory and methodology, and the others mainly address a range of specific hazards and human experience in coping with them. In this review we have also made use of The Second Assessment of Research on Natural Hazards in the United States (Mileti, 1999) and the final reports and appraisals of the International Decade for Natural Disaster Reduction presented at a conference in Geneva in July 1999 (Ingleton, 1999; ISDR, 2001).

The vitality of the research community that has produced these and many other books is impressive. We use the selected 12 as a starting point to examine the state of general understanding of natural hazards science, its changing focus, and the possible value of such understanding in reducing the negative consequences of hazards for humankind. To provide a comparative baseline we have used the first edition of 
Table 1

The following volumes were selected as representative of general publications during the $1990 \mathrm{~s}$

Blaikie, P., Cannon, T., Davies, I., Wisner, B., 1994. At Risk: Natural Hazards, People's Vulnerability, and Disasters. Routledge, London and New York, 284pp.

Bryant, E., 1991. Natural Hazards. Cambridge University Press, Cambridge, 312pp.

Burton, I., Kates, R.W., White, G.F., 1993. The Environment as Hazard. 2nd Edition. Guilford Press, New York and London, 290pp.

Coch, N.K., 1995. Geohazards: Natural and Human. Prentice Hall, Englewood Cliffs, NJ, 481pp.

Hewitt, K., 1997. Regions of Risk: A Geographical Introduction to Disasters. Longman, Edinburgh, 389pp.

Kovach, R.L., 1995. Earth's Fury: An Introduction to Natural Hazards and Disasters. Prentice Hall, Englewood Cliffs, NJ, 224pp.

Lindell, M.K., Perry, R.W., 1992. Behavioral Foundations of Community Emergency Planning. Hemisphere Publishing Corp., Washington, Philadelphia, and London, 320pp.

Palm, R.L., 1990. Natural Hazards: An Integrative Framework for Research and Planning. Johns Hopkins University Press, Baltimore and London, $184 \mathrm{pp}$.

Quarantelli, E.L. (Ed.), 1998. What is a Disaster?: Perspectives on the Question. Routledge, London and New York, 326pp.

Smith, K., 1996. Environmental Hazards: Assessing Risk and Reducing Disaster. 2nd Edition. Routledge, London and New York, 389pp.

Tobin, G.A., Montz, B.E., 1997. Natural Hazards: Explanation and Integration. Guilford Press, New York and London, 388pp.

Zebrowski Jr., E., 1997. Perils of a Restless Planet: Scientific Perspectives on Natural Disasters. Cambridge University Press, Cambridge, 1997, 306 pp.

our own work The Environment as Hazard (Burton et al., 1978) which describes our understanding of the state of knowledge in the 1970s. In examining the twelve volumes, we have considered how they differ in scope, context, and understanding from each other and what advances they reveal from earlier understanding. We recognize that such volumes may not always be pioneering in the introduction of new methods or findings, but that they do represent useful syntheses and reporting for the expanding number of scientists and policy makers both in the United States and internationally. Table 2 summarizes the major topics addressed by the selected volumes. One of them (Coch, 1995) cites examples primarily from the United States, but most examine experience in other parts of the world.

We found three important trends exemplified in this literature:

(i) a move towards greater emphasis on disasters and correspondingly less on the broader concept of hazards;

(ii) a growing convergence in research and practice across hazards, and;

(iii) a considerable expansion in exploration and adoption of concepts of vulnerability.

We also found that the examined volumes reflect in varying degrees and combinations three distinct views of causation, but beyond this, little in a way of new or evolving theory. In examining these trends and related ideas we consider the likely impact of the knowledge that they represent on the reduction of future losses.

Before addressing these questions about changes in thinking, we first consider what is known about trends in losses and gains. The data are incomplete but improving.

\section{Trends in losses and gains}

We begin with our understanding of the trends in losses and gains up to 1973 . We wrote:

To sum up, the global toll of natural disasters rises at least as fast as the increase of population and material wealth, and probably faster. In developing countries, disasters may be less frequent but are more catastrophic and more costly in lives (Burton et al., 1978, p. 2).

Today, it is clear that while loss of life from natural hazards is still large it is declining not only in the United States but also on a worldwide basis. Losses of property are large and continue to grow in the United States and worldwide. In addition, some kinds of losses are uncounted. Also the net benefits of locations and land use subject to hazard events are rarely considered. The growth of losses is independent of the frequency of hazard events, although some hazards exhibit nonrandom behavior with sustained periods of high or low frequency (e.g. Atlantic hurricanes and sub-Saharan drought). The losses of life have declined even more on a relative scale when growth in population is taken into account, and in developed countries losses of property may have increased no more than the growth in material wealth. In developing countries some catastrophic hazard events such as Hurricane Mitch in Honduras and Guatemala have caused damage equivalent to a decade's worth of economic growth, and in such cases the losses appear to be due to growth in vulnerability of expanding populations.

Most of the reviewed texts give examples of great losses from specific hazard events; some describe the current state of losses; few describe trends, and none give more than passing consideration to the gains or 
Table 2

Summary of content of selected recent hazards publications

\begin{tabular}{|c|c|c|c|c|c|c|c|c|c|c|c|c|}
\hline & $\begin{array}{l}\text { Blailie } \\
\text { et al. }\end{array}$ & Bryant & $\begin{array}{l}\text { Burton } \\
\text { et al. }\end{array}$ & Coch & Hewitt & Kovech & $\begin{array}{l}\text { Londell \& } \\
\text { Perry }\end{array}$ & Palm & Quarantelli & Smith & $\begin{array}{l}\text { Tobin \& } \\
\text { Montz }\end{array}$ & Zebrowski \\
\hline \multicolumn{13}{|l|}{ Natural } \\
\hline Avalanche (snow) & $\mathrm{T}$ & TT & $\mathrm{T}$ & TT & TT & $\mathrm{T}$ & & $\mathrm{T}$ & & TT & $\mathrm{T}$ & \\
\hline Drought & TT & TTT & TT & $\mathrm{T}$ & $\mathrm{TT}$ & TTT & & TT & $\mathrm{T}$ & TTT & $\mathrm{T}$ & \\
\hline Earthquakes & TTT & TTT & TT & TTT & TTT & TTTT & TT & TTTT & TT & TTT & $\mathrm{T}$ & TTT \\
\hline Erosion & $\mathrm{T}$ & $\mathrm{T}$ & & TTT & & TTT & & $\mathrm{T}$ & & & TT & $\mathrm{T}$ \\
\hline Floods & TTT & TTT & TT & TTT & TT & TTT & TT & TT & & TTT & TT & TT \\
\hline Mass movement & TTT & TTT & $\mathrm{T}$ & TTT & $\mathrm{TT}$ & TTT & $\mathrm{T}$ & TT & & TTT & $\mathrm{T}$ & \\
\hline Heat, cold & & & & & $\mathrm{T}$ & & & $\mathrm{T}$ & & TTT & $\mathrm{T}$ & \\
\hline Thunderstorms & & TT & $\mathrm{T}$ & & $\mathrm{T}$ & $\mathrm{T}$ & & $\mathrm{T}$ & & TT & $\mathrm{T}$ & \\
\hline Tornadoes & & TT & $\mathrm{T}$ & TT & $\mathrm{T}$ & TT & $\mathrm{T}$ & TT & & TT & TT & TT \\
\hline Tropical storms & TTT & TT & TT & TT & $\mathrm{T}$ & TT & $\mathrm{T}$ & TT & $\mathrm{T}$ & TT & TT & TT \\
\hline Tsunamis & $\mathrm{T}$ & TTT & $\mathrm{T}$ & TT & $\mathrm{T}$ & TT & $\mathrm{T}$ & $\mathrm{T}$ & & $\mathrm{TT}$ & $\mathrm{T}$ & TT \\
\hline Volcanoes & TTT & TTT & $\mathrm{T}$ & TTT & $\mathrm{T}$ & TTT & $\mathrm{T}$ & TT & & TTT & TT & TTT \\
\hline Wind & $\mathrm{T}$ & TTT & $\mathrm{T}$ & TT & $\mathrm{T}$ & TT & TT & TT & & TT & & TTT \\
\hline Winter storms & & TT & $\mathrm{T}$ & & $\mathrm{TT}$ & & & $\mathrm{TT}$ & & TT & $\mathrm{T}$ & \\
\hline \multicolumn{13}{|l|}{ Biological } \\
\hline Disease & TTT & $\mathrm{T}$ & $\mathrm{T}$ & & TT & & & & $\mathrm{T}$ & $\mathrm{T}$ & TT & TT \\
\hline Fire & & TTT & TT & $\mathrm{T}$ & $\mathrm{T}$ & TT & & & $\mathrm{T}$ & TTT & $\mathrm{T}$ & $\mathrm{T}$ \\
\hline Pests & TTT & & $\mathrm{T}$ & & TT & & & & $\mathrm{T}$ & & & \\
\hline Pollution & & & $\mathrm{TT}$ & $\mathrm{TT}$ & $\mathrm{T}$ & & $\mathrm{T}$ & $\mathrm{T}$ & & $\mathrm{T}$ & $\mathrm{T}$ & \\
\hline \multicolumn{13}{|l|}{ Technological } \\
\hline Hazardous material & $\mathrm{T}$ & & & TTT & $\mathrm{T}$ & & TT & $\mathrm{T}$ & $\mathrm{T}$ & $\mathrm{T}$ & $\mathrm{T}$ & \\
\hline Industrial accidents & $\mathrm{T}$ & & & & TT & TT & $\mathrm{T}$ & $\mathrm{T}$ & $\mathrm{T}$ & $\mathrm{T}$ & $\mathrm{T}$ & \\
\hline Structural failures & & & & & TT & TTT & $\mathrm{T}$ & $\mathrm{T}$ & & $\mathrm{T}$ & $\mathrm{T}$ & $\mathrm{TT}$ \\
\hline \multicolumn{13}{|l|}{ Social } \\
\hline Behavioral changes & TTT & TT & TTTT & & & & $\mathrm{T}$ & $\mathrm{T}$ & & TT & TTT & $\mathrm{T}$ \\
\hline Civil unrest & $\mathrm{TT}$ & TT & & & TT & & & & $\mathrm{T}$ & & $\mathrm{T}$ & \\
\hline Terrorism & & & & & TT & & & $\mathrm{T}$ & $\mathrm{T}$ & & $\mathrm{T}$ & \\
\hline War & $\mathrm{TT}$ & $\mathrm{T}$ & $\mathrm{T}$ & & TTTT & & & $\mathrm{T}$ & $\mathrm{T}$ & $\mathrm{T}$ & $\mathrm{T}$ & \\
\hline \multicolumn{13}{|l|}{ Complex } \\
\hline Desertification & $\mathrm{TT}$ & TT & $\mathrm{T}$ & $\mathrm{T}$ & $\mathrm{T}$ & TTT & & & & $\mathrm{T}$ & & \\
\hline Hunger & TTT & TT & $\mathrm{T}$ & & $\mathrm{T}$ & & & $\mathrm{T}$ & $\mathrm{T}$ & TT & & $\mathrm{T}$ \\
\hline Soil degradation & TT & TT & $\mathrm{T}$ & $\mathrm{TT}$ & & TTT & & & & $\mathrm{T}$ & & \\
\hline
\end{tabular}

T, Topic briefly mentioned or discussed in more detail; TT, Chapter heading(s) devoted to topic; TTT, Chapter devoted to topic; TTTT, Chapters devoted to topic.

benefits from locations, land use, and ecosystems subject to hazard. We are surprised by the lack of effort to draw and support larger conclusions. While some studies point out the lack of comprehensive data, few explain it and almost none address issues and remedies for this absence.

Turning to other literature, most recent efforts to appraise the validity of national or global estimates are very cautious (Mileti, 1999, pp. 65-104; Etkin, 1999, pp. 69-76). The basic data on costs and benefits of extreme events are incomplete and difficult to compare precisely. Further, there have been only a few careful studies of the full positive and negative consequences of efforts at hazard management on specific ecosystems.

Compared to estimates of physical damage, estimates of lives lost as a result of extreme events are much more comprehensive and probably more accurate. It is doubtful that any substantial incidence of human fatalities from these causes now goes unrecorded even in developing countries and in remote locations. Surveying the available reports for the United States and the world as a whole, it seems clear that notwithstanding the occasional heavy losses such as in the Turkish earthquake in July of 1999 the loss of human life and injury due to extreme natural events has been declining as proportion of the total population at risk.

The available evidence also suggests that physical damage has been increasing in volume. For example, one widely used source, the Geoscience Group at Munich Re, a major reinsurance company, concluded in 1998 that there were 707 large loss events "the highest number ever" (Munich Re, 1999). 
Factors responsible for the rising significance of natural disasters are seen as "the increase in the world's population and the settlement of areas that were previously uninhabited, as well as the development of highly sensitive technologies and their application in regions that are becoming more and more exposed. Added to this, there is the ever-growing density of values in large cities and industrial areas". (Munich Re, 1999, p. 5). The rising number of disasters is recorded in many places such as by the Worldwatch Institute (Abramovitz, 2001).

Available information does not permit strongly based conclusions beyond these broad observations. Even in the United States, for example, there is no single datacollection system for mutually consistent, uniform estimates of property damages directly caused by droughts, earthquakes, floods, hurricanes, and tornadoes. Responsibility is shared among a variety of public and private agencies, and there are no agreed criteria for taking into account the indirect losses, the market and depreciated value of the property and the cost of emergency measures taken to avoid direct damage. The recent Heinz Center report on the hidden costs in analyzing the full costs of coastal flooding emphasizes this (Heinz Center, 2000, pp. 45-104). But even this study of hidden costs does not include the costs of adjustment to prevent hazard losses.

The most consistent measure of losses is probably in reported insurance claims, but this misses many costs not covered by insurance. There is no generally accepted method of computing indirect losses to property owners and non-property owners, or of estimating losses to public agencies beyond replacement of damaged property. For these and associated reasons, the estimates of economic loss are incomplete in coverage, and, at best, very rough and it is therefore not surprising that the texts under review vary considerably in their treatment of the topic.

There have been a few efforts to express reported property losses as a proportion of estimated value of total property or to adjust the monetary value of damages to changes over time in the value of the monetary unit or as a proportion of the estimated national income (Yee and Yee, 1999). One such effort by Goklany (1999, 2000) examines property losses in the US from floods and hurricanes since 1926 when national estimates of the amount of property at risk (fixed tangible reproducible assets) became available. While there are clear indicators of growth in property losses from both these hazards, no similar growth is observed as a percent of material wealth.

Furthermore, there are very few efforts to estimate the net benefits of location or land use in hazard areas or the actual benefits from extreme events. Land and locations in areas subject to hazard have market value, often high market value. For informed buyers, such purchases should include consideration of hazard losses and net benefits over time. But buyers may not be informed, perceptions of risk may be confounded, and various subsidies of disaster insurance or relief may be provided. Nonetheless, some effort to calculate net gains and losses should be undertaken in the literature and its continued absence in these texts reveals a prevailing state of ignorance that the research efforts have scarcely addressed.

Hazard events themselves have benefits beyond the losses they initiate. It is recognized that in some ecosystems the high flood or long cold or hot spell may have a positive effect on natural phenomena. Quantitative assessments of beneficial consequences are rarely ventured. Obviously, those need to be evaluated alongside detrimental effects. When, for example, a flood overflows a reach of bottomland, there may be soil erosion but also deposition of silt and nutrients, and nourishment of floodplain ecosystems. Similarly, smaller forest fires may serve an important function in forest ecosystems and reduce the risk of more widespread and damaging events. Estimating quantitative monetary values for such effects may well be a misleading exercise.

While the unreliability of damage estimates is frustrating to the research community, there is little evidence that the decisions of the policy and practitioner communities would be substantially changed by more precise information. The consequences of extreme hazard events are now widely and dramatically reported, especially on television, and this has resulted in spasms of high level but generally short-lived attention.

\section{From hazards to disasters}

One significant feature of the literature of the past decade is the growing emphasis on "disasters" rather than "hazards" both in substance and in terminology. To some extent this distinction originally corresponded with a disciplinary tradition in which geographers carried out research on hazards and sociologists studied disasters. For example the joint investigation sponsored by the International Geographical Union in 1968-1976 based on methodological approaches developed by geographers at Clark University and the Universities of Chicago and Toronto, (White, 1974) considered the full extent of hazard events from relatively small scale deviations in natural variables to the most extreme events. Sociologists focused almost exclusively on the high magnitude events under the rubric of disaster research. The most comprehensive analysis of the social concept of disaster is made in the volume edited by Quarantelli (Quarantelli, 1998, pp. 1-8, pp. 234-273).

The distinction is important. The hazards orientation encourages attention to the beneficial as well as the adverse effects of natural variations. It also anchors 
responses into everyday life and livelihood and avoids "disaster exceptionalism" (Hewitt, 1997). On the other hand, research which focuses almost exclusively on the disaster end of the spectrum tends to increase emphases on the search for both social culpability or blame; description of the physical risks involved; and the emergency and short-term humanitarian response.

The press and other media have played a significant role in recent years in emphasizing the disaster end of the spectrum of natural hazards. There has been correspondingly much more attention at the government policy level to the disaster perspective than the hazards perspective. The naming of the International Decade for Natural Disaster Reduction (1990-1999) and its successor activity the International Strategy for Disaster Reduction, reflected this orientation.

The relative weight given to a "hazards view" compared with a "disasters view" has considerable influence on the kinds of adjustment that are preferred for study. Those scholars and others who adopt a broad hazards approach continue to emphasize the need for improvements in resource management, and the design of more effective hazard reduction strategies, comprising a wide spectrum of possible adjustments, including those increasing the net productivity of an area subject to extreme events. In contrast, those fixed upon the disaster end of the spectrum tend to emphasize the need for more thorough and more deep-seated scientific appraisal of physical phenomena and of social reform to reduce vulnerability.

By focusing on the initiating events; on forecasting and warnings; and on relief and humanitarian assistance, the disaster perspective has undoubtedly contributed in a major way to the reduction of fatalities and morbidity from hazard events. By the same token it has probably not helped to the same extent in advancing consideration of the wide range of adjustments that can be used to reduce vulnerability. Undoubtedly the attention to disasters and their immediate aftermath has made the development and successful implementation of mitigation more difficult. Major efforts are now underway to "change the culture" of disaster reduction in the direction of mitigation. This is seen in the policy innovations introduced by FEMA in the 1990s, and is further strengthened by the Second National Assessment (Mileti, 1999). The International Decade for Natural Disaster Reduction did not begin with a strong mitigation orientation but it increasingly led to the promotion of mitigation approaches, and this continues to be the aspiration of the successor program the International Strategy for Disaster Reduction. Neither in the United States nor in developing countries has the new interest in mitigation yet born major fruit in the reduction of losses.

\section{Converging hazard domains}

For many years the scientific interest in natural hazards was focused very largely on a few extreme events in geophysical systems. Those were principally avalanches, droughts, earthquakes, floods, high winds, landslides, tornadoes, tropical storms, and tsunamis. In recent years somewhat more attention has been given to extreme heat and cold, thunderstorms, lightning, and winter storms.

During the past two decades the definition of a hazard as reflected in some of these texts and as summarized in Table 2 has been expanded to include such biological phenomena as disease, pests, and water and air pollution. Grass and forest fires, whether initiated by humans or by lightning, also have been added. Another category of hazards results from complex interactions of physical, biological, and social systems and this now includes climate change, regional desertification, ozone layer depletion, soil profile degradation, acid rain, and loss of biodiversity.

To these natural phenomena there also has been added another stream of research on primarily technological phenomena such as release of hazardous materials in the workplace, industrial accidents, and failure of routine structures and operational plans. The insurance industry has become more deeply involved in natural hazard concerns (Britton and Oliver, 1991; Kunreuther and Roth, 1999). More attention has been paid to combinations of factors, such as age, economic class, ethnicity, and gender, leading to differential changes in type of risk and in social behavior, and to such extreme manifestations of social hazard as civil unrest, local terrorism, and organized war.

It seems probable that this convergence and integration of hazard domains has strengthened response in some ways, but may have weakened it or had little impact in others. By raising the profile of emergency preparedness, stronger and more effective emergency management systems have been created. Simultaneously a cultural shift in the direction of greater risk aversion especially in relation to technological hazards has taken place, and the adoption of risk assessment methods has led to more careful comparison of benefits in relation to risks. The intense scrutiny now routinely given to technological innovations (genetically modified organisms and other medical biotechnology products and services for example) and the acute sensitivity of civil society organizations are testimony to this trend. Surprisingly however, this has not carried over to comparable concern about the creation of new and enlarged risks from natural hazards. Could it be that convergence in helping to create a larger domain of common scientific and professional management expertise has facilitated attention (some would say over attention) to newer hazards and correspondingly dimin- 
ished attention to the better known and more "traditional" natural hazards? Indeed, the whole convergence movement may be more driven by academic and scientific curiosity than by a recognition of the opportunity to transfer lessons and experience from one hazard to another, although the integration of risk analysis continues to challenge the scientific and policy communities (German Advisory Council on Global Change, 1998).

\section{Focusing on vulnerability}

In the space of two decades vulnerability has emerged as a central concept in many of the reviewed books. Vulnerability appears in the indexes of seven of the 12 volumes, while the number of relevant pages indexed extends to several hundred. In Blaikie et al., (1994) and Hewitt it is the defining concept. The meaning of the concept varies widely between volumes and thus reflects both the widespread use of the term and the absence so far of consensual definition and measurement. (For a review, see Cutter, 1996).

There appear to be at least three major uses of the term. One is its commonplace meaning: being prone to or susceptible to damage or injury (Blaikie, p. 9) from natural hazards. That is the most widely used concept. For example, vulnerability, in the latest IPCC climate change assessment, is seen as negative sensitivity or the degree to which a system is susceptible to injury, damage, or harm by climate stimuli (See Smit et al., 2000 for a glossary of related terms). This is the use found in the first edition of The Environment as Hazard (Burton et al., 1978). A variant of this usage is sensitivity to multiple stresses from differing hazardous events. Here, the potential for loss arises from a range of threatening and interacting events and conditions such as the way vulnerability to drought in the United States increased in the 1930s by the simultaneous occurrence of drought and economic depression.

In a second usage the concept of vulnerability implies a measure of risk combined with the level of social and economic ability to cope with the resulting event (Smith, p. 25). In this usage vulnerability to hazards combines both the degree of exposure or sensitivity to a threat and the adaptive capacity to respond to such threats. Its opposite connotation is resilience. Our 1978 volume suggested: "Nature, technology, and society interact to generate vulnerability and resilience vis-à-vis disaster" (Burton et al., 1978, p. 223; see also Smith, pp. 25-26).

Blaikie et al. (p. 9) in a third usage further refines such meaning by embodying vulnerability in specific group characteristics.

By "vulnerability" we mean the characteristics of a person or group in terms of their capacity to anticipate, cope with, resist, and recover from the impact of a natural hazard. It involves a combination of factors that determine the degree to which someone's life and livelihoods are put at risk by a discrete and identifiable event in nature or in society.

Some groups in society are more prone than others to damage, loss and suffering in the context of differing hazards. Key characteristics of these variations of impact include class, caste, ethnicity, gender, disability, age, or seniority.

In all of these meanings, there is an implied interaction between nature and society, but these different meanings also imply differing views of causation from an emphasis on natural hazard vulnerability in its commonplace meaning, to interactive events of both nature and society, and to distinctly human and social conditions of person or group at some place (see Cutter, 1996, p. 533). Thus, while vulnerability is a key concept in most of the volumes, its varied meanings presage the changing views of causation to which we turn below.

In the years ahead, it can be expected that differences in interpretation of vulnerability may be sorted out, and relatively standard measures of vulnerability will emerge. These will combine both measures of exposure and sensitivity to hazard and of adaptive capacity and will be used to inform preventive action to diminish the burden of hazards. (See, for example, Clark et al., 1998; Cutter et al., 2000; Moser et al., 1998; and Ratick et al., 1998).

As in the case of the move towards a "disaster" focus it seems likely that the attention to vulnerability has had, and will have a continuing impact in helping to reduce mortality and morbidity, especially in developing countries and especially among the poorer and more vulnerable groups. The concept of vulnerability also helps in the promotion of the involvement of communities and citizens groups in the planning and development process, and contributes to the goals of empowerment, democratization, and the advancement of human rights. At the same time the concern with vulnerability can be used to direct attention towards ideological debates concerning its alleged origins in feudalism, capitalism, globalization and the like, and away from the more mundane, but nevertheless practicable, steps that can be taken to mitigate hazards by the deployment of a wider range of adjustments.

\section{Changing views of causation}

On one level, changes in understanding natural hazards correspond to changes in worldviews as to their causation. To what extent are natural hazards acts of nature, acts of society, or the results of interaction 
between nature and society? And what do such views imply for responding to hazards? As exemplified by the selected texts, there has been a clear shift over time along the nature-society continuum of views of causation. Much more responsibility is now laid at the door of human acts of omission and commission. Yet there are echoes of all three explanations in these books.

This distinction between natural disasters as caused by forces external to human beings and caused by human actions has characterized the search for explanation for millennia. Thus, the old biblical idea of disasters as Acts of God include the notion of a God acting in response to human failings. Disasters were not simply visited upon humans in a capricious and random way but were seen as an expression of a vengeful or wrathful God justifiably displeased with human behavior. The same pattern of ideas persists in some quarters today as seen, for example, in explanations of the epidemic of HIV, which some fundamentalists argue is just punishment for behavior they see as immoral.

A second view seeks to find human culpability as the root cause. There are many variants on this underlying idea. These range from the search for careless mistakes or errors of judgment to suggestions of deliberate and malevolent or self-seeking choices on the part of individuals or groups. The most common explanation favored in the recent literature under review is that underlying social forces and processes are to blame. At the extreme, these include broad causative designations such as feudalism which it is claimed is responsible for forcing the poor and powerless members of the community into the most dangerous locations (e.g., in Pakistan) to capitalism and neo-colonialism, which may have the same end result for those with the lowest incomes or political power. Less ideological views along similar lines tend to associate disasters with the impersonal workings of social and economic forces.

Most of the texts we have reviewed accept that all natural hazard situations arise from an interaction of human society and the natural environment. People seeking livelihood or simply the amenity and recreation value of hazard-prone lands, or people pushed into dangerous areas by virtue of poverty and land scarcity, are all examples of the interactive process at work. The extent to which nature, or God, or forces external to human beings, can be blamed is a function of human knowledge and the utilization of that knowledge in choosing hazard avoidance or reduction. Texts which emphasize the geophysical causes of hazards also specify the causal chains involving plausible failure and the perception of risk by individuals (Kovach, 1995, pp. 146-184). With the advance of scientific understanding, and the capacity to define hazard zones precisely and to estimate hazard event magnitude and frequency, there is less and less justification for the placing of responsibility beyond the realm of human action.
There is a trend in much of the reviewed literature for the interactance view to be overshadowed by the enthusiasm for blaming society for its own vulnerability (Mileti, 1999). A measure of this shift towards the social construction of disasters is the growth in the attention to and focus upon the concept of vulnerability. As discussed above, the idea of vulnerability and its causes has become central in many but not yet all of the hazards debates.

While the recent hazards literature places greater and greater emphasis on the social cause of disasters, the social causes are numerous and complex and not easily corrected or removed. The next phase in hazards research is likely to involve a much greater sophistication in the analysis of social causes. This may lead to further categorization and classification of those causes according to different hazard situations and different social and cultural circumstances.

The trinity of views as to causation may also persist. Novel and surprising hazards will continue to be identified. An example was the devastating release of carbon dioxide by Lake Chad. Another was the tidal wave that engulfed some villages on the north coast of Sumatra in August 1998 and was caused by an undersea earthquake. In other situations the social explanation of self-created vulnerability may offer the most accepted explanatory view, as in the conscious location of a new structure in a known floodplain.

While the balance of evidence or preference for blaming nature or blaming humans may shift, it seems clear that both forces will always remain in play. Consider the severe drought and forest fires that occurred in Indonesia and Papua New Guinea in late 1997 and early 1998. That drought has been associated with a strong El Niño episode and was predicted by meteorologists. Some commentators have noted that little advance precautionary measures were taken in spite of the warning. Other commentators noted that indigenous populations were seeking to expand settlement into hitherto uncleared and unoccupied forestlands. The traditional method of expansion is to burn the forest, and it is suggested that some of the controlled burning for settlement purposes may have got out of hand and led to more widespread fires. An even more severe explanation is found in the rumors that mining and lumber companies, anxious to open up the interior, took advantage of the severe dry period to set fires.

\section{Explanatory paradigms}

In general, hazard research has never been strongly theoretical, preferring instead empirical studies or policy applications. Over time, however, there has been a growing interest in theory, some of which can be found in the volumes under study. We have characterized this 
theoretical interest as three approaches (Burton et al., 1993, p. 252). The first is the application to hazard domains of existing "grand theories" such as the utility or optimizing theory of neoclassical economics, or the underdevelopment theory of neo-Marxist political economy, or the environmental determinism of an earlier geography. A second approach has been a kind of selective eclecticism (Kates, 1988), the assemblage of a range of theoretical perspectives to provide a conceptual or theoretical framework. Thus, Palm (1990, pp. 18-24) selects from theories of culture, decision-making, political economy, and social organizations to create her integrative framework to address both individual decisions and societal structure. Thirdly, some distinctive hazard theories seek to generalize or explain empirical observations on unique intersections of nature, technology, and society that characterize hazard origins, adjustments, and trends, as in Tobin and Montz (1997) (pp. 5-7), and see them as undergoing evolution.

\subsection{Hazard origins}

Theories of hazard origins are closely linked to the major causative views described above and in general are derivative of grand or eclectic theories. Distinctive to the hazard field is an interactive theory of hazard origins that asserts that natural hazards are encountered in the search for the useful. Natural hazards and natural resources are intricately related. For example, ideal locations for human settlement providing access to multiple resources (coasts, floodplains, piedmonts) also create exposure to multiple hazards. At such sites, nature, society, and technology interact to generate both vulnerability and resilience to hazard. Thus, there are actually no uniquely distinctive natural, social, or technological hazards although convention persists in such distinctions.

Most of the volumes under study accept such an interactive view. Major differences revolve around some long-standing theoretical and empirical views as to the origins of hazard vulnerabilities, differences that partly reflect the different meanings of vulnerability described above, and partly from different conceptions of poverty as a source of vulnerability. While the volumes that address vulnerabilities consider poverty as a major explanatory variable, there are significant differences in equating the poorest with the most vulnerable. One such difference is the expectation that vulnerable societies, while poor as compared to industrialized countries, were not the poorest of the poor, thus rejecting absolute poverty as the measure of vulnerability, a theoretical expectation found in a least two of the volumes under review. Blaikie, et al., suggest that vulnerability and poverty are not synonymous, although they are often closely related (Blaikie, et al., p. 60). The risk faced by people must be considered as a complex combination of vulnerability and hazard (Blaikie et al., p. 21).

\subsection{Hazard adjustment}

To cope with natural hazards, people and their societies adjust and adapt. These actions are variously termed human responses, coping actions, mitigating actions, adjustments, and adaptations. Theories of the middle-range have addressed the nature, range, and accessibility of such actions and the ways in which they are selected and implemented. Thus, some theory holds that there are generic sets of adjustments applicable to all hazards, but the capacity to undertake them may be severely limited for any individual or group. Those accessible adjustments are selected and implemented in a general sequence of increasing awareness, difficulty and concern, but rarely in a fashion that is optimal with respect to an assumption of universal accessibility and knowledge of costs and benefits. Over time some shortterm adjustments become part or fabric of adaptation and are integral in the behavior of life and livelihood.

These theories have changed little since the earlier period with the exception of much greater sensibility to how accessibility to important adjustments may be limited often to those that need them the most. Thus, Hewitt concludes "disaster is seen here as an integral part of everyday or ordinary life". Rather than "islands" where extreme events occur, the geography of disasters reveals where vulnerable people live (p. 355). With this exception, few of the texts address such theory directly. Indeed, much of the interest in responding to hazard has shifted to technological and environmental hazards, where under such rubrics as risk assessment and emergency management, these methodological and theoretical issues have been revisited with substantial improvement in conceptual understanding and detail (Lindell and Perry, pp. 1-26). One result has been the creation of a theory of social amplification of risk, (Kasperson et al., 1988) increasingly addressed to such hazards.

\subsection{Hazard trends}

The universal process of adaptation has led to theoretical expectations of hazard trends stated as three generic hypotheses (Burton et al., 1978; Bowden et al., 1981). The lessening hypothesis expects that by broadening the range of effective adjustments, the cumulative effect of development in societies and nations is the reduction of the social costs of hazard to society, especially the death toll. This seems to be empirically demonstrated for deaths. But such development may actually increase property vulnerability in the short run as the transition hypothesis proposes: that in periods of rapid social and economic change marking develop- 
ment, societies may become peculiarly vulnerable to hazard as older forms of adjustment may deteriorate before new forms become available. Thus, in many developing countries, rapid urbanization may be marked by poor construction and the expansion of squatter settlements without community planning, often on hazardous sites. And when disaster occurs, traditional systems of sharing are no longer in place while the substitute systems of organized relief and welfare are still poorly developed. A third hypothesis posits that some effective short-run human adjustments might actually increase the long-run vulnerability. The floodplain levee serves as the model for such effects: levees intended to prevent damages from a flood of stated magnitude, when over-topped actually increase catastrophe (White et al., 1958). Thus, the catastrophic hypothesis suggests that successful lessening of hazard at one time may serve to increase a population's vulnerability to a later catastrophic perturbation that exceeds the level of traditional adjustment.

The texts consider in a variety of ways the range of theories as to the effects of the prevailing social and political systems upon response to natural extremes, as in Bryant's comparison of Marxist and capitalist policies (pp. 7-8). All of the texts recognize in some fashion the range of relationships between social and natural systems, and some call special attention to the basic importance of maintaining the integrity of the ecosystem (Bryant, 1991, pp. 6-8; Coch, pp. 10-13; Zebrowski, 1997, pp. 285-287, 345-398).

\section{Explaining why more is known and more is lost}

This review of recent progress in coping with natural hazards obliges us to attempt a summary of where we now stand, and what priority needs should be addressed. We have noted that the losses of life from natural hazards, while still large, are declining not only in the United States but also on a worldwide basis. At the same time losses of property are large and continue to grow in the United States and globally. Given the growth in knowledge could better results have been expected? The decrease in lives lost could have been achieved more rapidly and still remains at an unacceptably high level. The rapid increase in property losses should have been first ameliorated and then reversed. The fact that this has not happened should not necessarily be counted a total failure. Without the efforts made by the scientific community, through the work of the International Decade for Natural Disaster Reduction and elsewhere, things might have been much worse. Recognizing that these efforts have nevertheless fallen well short, what explanations can be found?

Five possible explanations are suggested. We consider that they all have some validity in some cases, but that there is no value and some danger in attempting an heroic globally integrated synthesis of the explanatory power of each.

1. To what extent is it that knowledge is lacking and that the management of natural hazards continues to be flawed by significant areas of ignorance?

2. To what extent is it that knowledge is available but not used?

3. To what extent is it that knowledge is used, but in an ineffective manner and even with results contrary to those planned or expected?

4. To what extent is it that knowledge is available; is used effectively, but that it simply takes time for knowledge to be applied and take effect?

5. To what extent is it that knowledge is available; is used effectively, and produces positive results, but that the best efforts have simply been overwhelmed by the scale and speed of the processes that lead to the increase in vulnerability for some people and places through population growth, economic expansion, and greater material wealth and through greater poverty and lack of empowerment elsewhere?

In the text that follows we offer some preliminary thoughts about these reasons, and draw two main conclusions.

Is knowledge lacking? There is no doubt that the physical science understanding of the processes generating natural extremes has advanced considerably in recent decades, and that in many cases of atmospheric hazards forecasting and warning abilities has improved dramatically. Knowledge of where hazard events will occur, their probability and potential magnitude has also increased. There is also a much deeper understanding of the social forces and human actions that have led to growing vulnerability in many situations. (Burby et al., 1998). While the case for more research and the need for greater knowledge are always difficult to refute, we conclude that in the United States and other developed countries a lack of knowledge is not a major contributory factor to the growth of disaster losses. In many developing countries the fundamental scientific understandings are also known and appreciated, but governments frequently lack the funds to develop precise understandings of the actual distribution and potential magnitude and frequency of hazards events or the resources or will to address the social forces and human actions that have increased vulnerability. In general, progress has been slow in increasing adaptive capacity in poor countries. Call for more resources or an end to poverty are justified but do not themselves provide specific answers.

Is knowledge not used? There is perhaps more reason to attribute rising losses on the failure to act. Given modern communications, and the great accessibility of knowledge and information, and given the internation- 
ally recognized severity and urgency of the disaster issues it may seem surprising to suggest that failure to act is widespread. Yet there is evidence that in developing countries disasters continue to take people, communities and governments by surprise and that insufficient preparation has been made to deal with emergencies, even though this has been a major thrust of international activity. Longer-term and more farsighted programs to reduce vulnerability through disaster mitigation are conspicuous by their absence. This probably reflects lack of resources, other pressing priorities, and lack of adaptive capacity. In many countries it is made more difficult by the inability or unwillingness to address the underlying poverty, inequalities, and corruption that make for great vulnerability. There is evident need for more assistance to developing countries in the field of disaster mitigation and vulnerability reduction. What is needed is more than emergency disaster relief and rehabilitation, but the long-term strengthening of the capacity of developing countries to design and execute their own mitigation and vulnerability reduction efforts.

Is knowledge used ineffectively? The case for this explanation seems, perhaps paradoxically stronger in developed countries where policy and administration might be expected to be more effective. In the United States and other developed countries there is abundant accessible knowledge, and financial resources are also available. Many programs have been developed over the years to manage natural hazards from flood control to earthquake building codes, to land use regulation, to insurance. Despite the many good intentions these programs often seem to have failed to produce the anticipated results. Flood control projects have served to encourage more floodplain development. Federal disaster assistance in some areas has encouraged continued occupancy of areas with repetitive losses (Conrad, 1998). Earthquake building codes have not been properly enforced. Land use regulations have been opposed through aggressive legal action and have often been applied with a lack of conviction, or have been subject to frequent variances obtained by political means. Insurance, even when coupled to land use regulation, has probably increased not reduced losses by encouraging growth in hazardous areas. (US Congress, 1966). Conflicting interests and lack of political will to resolve them seems to be at the base of many failures to apply knowledge effectively.

Is there a time lag? While it would be reassuring to think that the effective use of knowledge is now in place and that it is only a matter of time before the beneficial results of knowledge and policies begin to be reflected in reduced disaster losses, there is little reason for complacency on this score. The record of attempts to manage natural hazards is at best a very slow and mild success story and there seems little reason to expect fundamental change in the near term. Incremental improvements in hazard management have been occurring for some decades at least. The steady reduction in loss of life shows that short-term actions associated with warnings, forecasts and evacuations have had significant effects. But the longer sustained attention that is required for disaster mitigation seems to have remained beyond reach. Disasters occur very infrequently in any one place, and with the passage of time the determination to maintain mitigation policies weakens in the face of demands for the more immediate benefits to be obtained from taking risks especially when they can be passed on to others (Burton and Lim, 2001).

Is an overwhelming increase in vulnerability the cause? It appears likely that in the United States and other industrialized countries, disaster losses have grown with population and economic growth, but have not increased significantly as a portion of national wealth. While the distribution of losses may have fallen unequally on some regions and some social groups, there has been no compelling macro-economic reason for concern. States, communities and individuals still have reason to take risks with natural hazards in the hope that they will be spared, and to expect that in the unlikely event of disaster the Federal Government will come to their aid. And despite all the rhetoric from the Federal Emergency Management Agency about disaster mitigation there are no compelling reasons to believe that mitigation actions will be given high enough priority, or will be applied effectively or will have sufficient political backing to make much difference. As long as disaster losses can be absorbed by an economically rich society, the motivation for action to counteract losses due largely to growing wealth is not likely to be strong enough.

In developing countries the story is quite different. On top of other factors, the pace of population growth; the expansion of human settlements; and short-term development directed to economic growth, an increase in wealth and an assumed reduction in poverty, are all part of the pattern of unsustainable development and growing vulnerability. This does serve to overwhelm the modest efforts to manage hazards. Recurrent themes running though recent disasters in places as different as Honduras and El Salvador, India, and Turkey tell of expanding human settlements with people, often poor, forced to live on faults, floodplains, hillsides, and mountain slopes in dangerous settings and in poorly constructed and inspected buildings.

We offer two concluding observations in this context. The first is that better appraisal is needed of the actual results at community and other levels of applying the best available knowledge in the best possible way. The second is that there is a need to build upon past achievements in creating more understanding of natural hazards, by better integration of the knowl- 
edge into the wider efforts directed at sustainable development.

Insufficient attention has been given to the analysis and evaluation of productive efforts to apply all available knowledge to the execution of hazard mitigation measures in specific communities. In the United States, for example, while there have been a variety of experiments in "project impact" communities under FEMA, there has not yet been a truly discerning examination of the major lessons to be drawn from the concrete programs that have been carried out. The case of Tulsa, Oklahoma, which has led the way in its comprehensive approach to flood and tornado hazard, is an example deserving appraisal. The appraisals that are needed should be in the broader context of community planning.

While wishing to see reinforcement and strengthening of current efforts, our analysis makes us acutely aware that more is needed. In the prescription based on the second (US) natural hazards assessment, Mileti and associates call for a "culture shift" in the United States and throughout the globe that would integrate natural hazards mitigation "into the daily activities of everyone who has an influence on future losses" (Mileti, 1999, p. 267). Could such an ambitious and evangelical vision add significantly to the record of partial achievements that can be attributed to the countless national and international commissions and programs, innumerable policy innovations, endless scientific research, and unceasing media coverage? We hope that this is the case. Major "culture shifts" have occurred in the past and will doubtless continue to occur. Can natural hazards and sustainable development become the content of such a shift or transition?

This would be consistent with the progressive broadening of the theoretical framework and practical content of hazards research. Hazards research in the 1960s was criticized for its use of extreme geophysical events as a starting point for analysis. This focus on extreme events in nature, it was asserted, failed to take account of the human ecology of everyday existence, and even implied a simplistic determinism, or a unidirectional causal relationship from geophysical events to impacts to human response. This critique helped to generate the move towards the concepts of vulnerability which have become so central in current thinking. A second and related critique of early hazard research found it to be too dependent upon the use of choice and decision models and reliant upon such psychological constructs as individual perception of risk. This assumed that people could exercise choice and were masters of their fate to a much greater degree than now seems valid. By focusing on behavioral choice the research seemed to be blaming the victim. Along with growth of interest in the concept of vulnerability has come a recognition of the role of broader, deeper and more powerful social forces which constrain choice and which cannot be countered with technical or social fixes. Thanks to such critical analysis, hazards research has now reached a new level of maturity and complexity. The task at hand seems to require a new synthesis in which the varied dimensions of the hazards problem can be integrated in an internally consistent way with broader environment and development goals.

Notwithstanding some current frustrations there are signs that the "hazards community" is ready and eager for change. Increasingly it is understood that the "natural hazard problem" is deeply embedded in the larger question of sustainable development, and the specific issues of reducing poverty, improving governance, increasing equity, and limiting climate change with its threat of increased extreme events. Thus the challenge for the hazards community is to build upon the past record, and move on to find ways to effectively link our growing knowledge of hazard vulnerability to the larger issues and needed actions of a sustainability transition (US, National Research Council, 1999). There is hope for a less hazardous environment, and its achievement will depend upon the linking and convergence, and the integration, of hazard studies into the larger consciousness of sustainability and equity.

\section{Acknowledgements}

The authors are indebted to David Morton and Sarah Michaels for assistance with bibliographic references; to Betsy Forrest for examination of the selected texts; and to Jackie Monday and Tom Downing for constructive comments upon a draft of the paper.

\section{References}

Abramovitz, J.N., 2001. Unnatural Disasters, Paper 158, Worldwatch Institute, Washington, 62pp.

Blaikie, P., Cannon, T., Davies, I., Wisner, B., 1994. At Risk. Natural Hazards, People's Vulnerability and Disasters. Routledge, New York, 284pp.

Bowden, M.J., et al., 1981. Effect of Climate Fluctuations on Human Population: Two Hypotheses. CENTED, Worcester, 34pp.

Britton, N.R., Oliver, J., 1991. Financial Risk Management for Natural Catastrophes. Aon Group Australia, Brisbane, 283pp.

Bryant, E., 1991. Natural Hazards. Cambridge University Press, Cambridge, 312pp.

Burby, R., et al., 1998. Cooperating with Nature: Confronting Natural Hazards with Land-use Planning for Sustainable Communities. Joseph Henry Press, Washington, DC, 356pp.

Burton, I., Lim, Bo., 2001. An Adaptation Policy Framework. Capacity Building for Stage II Adaptation. United Nations Development Programme, New York.

Burton, I., Kates, R.W., White, G.F., 1978. The Environment as Hazard. Oxford University Press, Oxford, 240pp. 
Burton, I., Kates, R.W., White, G.F., 1993. The Environment as Hazard. 2nd Edition. The Guilford Press, New York, 290pp.

Clark, G., et al., 1998. Assessing the Vulnerability of Coastal Communities to Extreme Storms: The Case of Revere, MA. Mitigation and Adaptation Strategies for Global Change, Vol. 3, pp. 59-82.

Coch, N.E., 1995. Geohards: Natural and Human. Prentice-Hall, Englewood Cliffs, $481 \mathrm{pp}$.

Conrad, D., et al., 1998. Higher Ground. National Wildlife Federation, Vienna, VA, 199pp.

Cutter, S., 1996. Vulnerability to environmental hazards. Progress In Human Geography 20 (4), 529-589.

Cutter, S., et al., 2000. Revealing the vulnerability of people and places: A case study of Georgetown county, South Carolina. Annals of Association of American Geographers 90 (4), 718-737.

Etkin, D., 1999. Risk transference and related trends; driving forces towards more mega-disasters. Environmental Hazards 1 (2), 69-75.

Goklany, I.M., 1999. Richer is more resilient: dealing with climate change and more urgent environmental problems. In: Bailey, R. (Ed.), Earth Report 2000. The True State of the Planet Revisited. McGraw Hill, New York.

Goklany, I.M., 2000. Potential consequences of increasing atmospheric $\mathrm{CO}_{2}$ concentration compared to other environmental problems. Technology 75, 127-213.

Heinz Center for Science, Economics and the Environment, 2000. The Hidden Costs of Coastal Hazards. Island Press, Washington, DC and Covelo, CA, 220pp.

Ingleton, J. (Ed.), 1999. National Disaster Management. Tudor Rose, Leicester, UK, 320pp.

International Federation of Red Cross and Red Crescent Societies, 2001. World Disaster Report: Focus on Recovery. Geneva, 248pp.

ISDR, 2001. International Strategy for Disaster Reduction. Collection of UN Documents on Disasters, Geneva.

Kasperson, et al., 1988. Emergency planning for industrial crises: an overview. Industrial Crisis Quarterly 2 (2), 81-87.

Kates, R.W., 1988. Theories of Nature, Society, and Technology. In: Erik Baark, Uno Svedin (Eds.), Man, Nature, and Technology: Essays on the Role of Ideological Perception. Houndmills, UK, Macmillan Press, pp. 7-36.

Kovach, R.L., 1995. Earth's Fury: An Introduction to Natural Hazards and Disasters. Prentice Hall, Englewood Cliffs, NJ, pp. 146-184.
Kunreuther, H., Roth, R. (Eds.), 1999. Paying the Price: The Status and Role of Insurance Against Natural Disasters in the United States. Joseph Henry Press, Washington, DC.

Lindell, M.K., Perry, R.W., 1992. Behavioral Foundations of Community Emergency Planning. Hemisphere Publishing Corp., Washington, Philadelphia, and London, 320pp.

Mileti, D.S., 1999. Disasters by Design. Joseph Henry Press, Washington, DC, 351pp.

Munich Re, 1999. Annual Review of Natural Catastrophes. Munich Re, Munich, 20pp.

Munich Re-insurance, 2001. Annual Review of Natural Catastrophes, 2000. Munich, Germany, 56pp.

National Research Council, 1999. Our Common Journey: A transition toward sustainability. National Academy Press, Washington, DC, 363pp.

Palm, R.L., 1990. Natural Hazards: An Integrative Framework for Research and Planning. Johns Hopkins University Press, Baltimore and London, 184pp.

Quarantelli, E.L. (Ed.), 1998. What is a Disaster? Routledge, New York, pp. 1-8 and 234-273.

Ratick, K., Dow, Meyer, W., Emani, S., Jin, W., Kasperson, J., Kasperson, R., Schwarz, H., 1998. Assessing the vulnerability of coastal communities to extreme storms: the case of Revere, MA, USA. Mitigation and Adaptation Strategies for Global Change 3, 59-82.

Smit, B., Burton, I., Klein, R.J.T., Wandel, J., 2000. An anatomy of adaptation to climate change and variability. Climate Change 45, 223-251.

Tobin, G.A., Montz, B.E., 1997. Natural Hazards: Explanation and Integration. Guilford Press, New York and London, 388pp.

United States. 89th Congress, 2d Session. 1966. A Unified National Program for Managing Flood Losses House Document No. 465, 47pp.

White, G.F. (Ed.), 1974. Natural Hazards: Local, National, and Global. Oxford University Press, New York, 288pp.

White G., et al., 1958. Changes in Urban Occupance of Flood Plains in the United States. University of Chicago Department of Geography, Research Paper 57, Chicago, IL, 235pp.

Yee, C.L, Yee, B.C., 1999. A study of effectiveness of flood mitigation measures, Proceedings of Rivertech 96, First International Conference on New Emerging Concepts for Rivers, Chicago, IL, pp. $555-562$.

Zebrowski Jr., E., 1997. Perils of a Restless Planet: Scientific Perspectives on Natural Disasters. Cambridge University Press, Cambridge, 306pp. 